\title{
Relation of Chemerin to Insulin Resistance, Inflammation and Obesity in Egyptian Type II Diabetics
}

\author{
Nadia M. Abdallah ${ }^{1}$, Tahany M. Abd El-Moneam ${ }^{2}$, Magda K. Ezz ${ }^{1}$ and Eman A. M. M. Taha ${ }^{1}$ \\ ${ }^{1}$ Biochemistry Department, Faculty of Science, Ain Shams University, \\ ${ }^{2}$ Endocrinology Unit, Ain Shams University Hospitals
}

\section{A R T ICLE INFO}

Article history:

Received 23 March 2015

Accepted 26 April 2015

Keywords:

Chemerin:

insulin resistance;

inflammation;

obesity;

type II diabetes mellitus.

\begin{abstract}
A B S T R A C T
Chemerin is a newly discovered adipokine that regulates adipocyte development and metabolic function, as well as immune functions. Chemerin may mediate a link between obesity, inflammation, insulin resistance and type 2 diabetes mellitus. Therefore, the aim of this study was to investigate the relationship between serum chemerin, insulin resistance, inflammatory markers and obesity in Egyptian type II diabetics. 120 subjects were included in this study, subdivided equally into four groups as follows: GI: Lean controls, GII: Lean diabetics, GIII: Obese controls and GIV: Obese diabetics. The following biochemical parameters were estimated in this study: serum chemerin, fasting and postprandial plasma glucose, glycated hemoglobin, serum insulin, total cholesterol, triacylglycerols, low and high density lipoprotein-cholesterol, as well as tumor necrosis factor- $\alpha$ and interleukin-6. Body mass index, homeostasis model assessment for insulin restistance and homeostasis model assessment for $\beta$-cells function were calculated. Results revealed that serum chemerin levels were significantly higher in diabetic patients and obese subjects compared with lean controls. In addition, serum chemerin levels were positively correlated with age, body mass index, fasting and postprandial plasma glucose, serum insulin, homeostasis model assessment for insulin restistance, total cholesterol, triacylglycerols, low density lipoprotein-cholesterol, tumor necrosis factor- $\alpha$ and interleukin-6. Moreover, a negative correlation was found between serum chemerin, homeostasis model assessment for $\beta$-cells function and high density lipoprotein-cholesterol. In conclusion, serum chemerin is associated with insulin resistance, inflammation and obesity in Egyptian type II diabetics.
\end{abstract}

\section{Introduction}

Diabetes mellitus is one of the most common chronic diseases in nearly all countries and continues to increase in numbers and significance, as changing life styles lead to reduced physical activity and increasing obesity. Globally it was estimated that 382 million people have diabetes and the number of diabetics will rise to 592 million by 2035. As well as, it was estimated that diabetic Egyptians in 2014 were 7.59 million ${ }^{[1]}$.

Adipose tissue secretes adipokines which are important regulators for its development and function. These adipokines include adiponectin, leptin, omentin, resistin, retinol binding protein-4, tumor necrosis factor- $\alpha$ (TNF$\alpha$ ), interleukin-6 (IL-6), vaspin, visfatin and chemerin ${ }^{[2]}$. Adipokines have a significant influence on glucose metabolism in various tissues and influence overall ene-

* Corresponding author.

E-mail address: eahmed52@ymail.com rgy balance at the systemic level ${ }^{[3]}$. It is belived that dysregulation of adipokine secretion in obesity plays an important role in the pathogenesis of obesity-related insulin resistance and type II diabetes mellitus (T2DM) [4].

Chemerin is an adipokine also known as retinoic acid receptor responder protein 2 and tazarotene-induced gene $2^{[5]}$. It is secreted as a $18 \mathrm{kDa}$ inactive proprotein which undergoes proteolytic proceesing to generate the $16 \mathrm{kDa}$ active chemerin which present in plasma and serum ${ }^{[6]}$. Chemerin acts by binding to chemerin receptors which are G-protein coupled receptors and include CMKLR1, GPR1 and CCRL2. Chemerin has been shown to regulate adipocyte differentiation and modulate the expression of adipocyte genes involved in glucose and lipid metabolism ${ }^{[7]}$, also it serves as a chemoattractant agent, promoting chemotaxis of CMKLR1-expressing leukocyte population, such as human macrophages, 
immature dendritic cell and natural killer cells to localized sites of inflammation, suggesting a proinflammatory role ${ }^{[8]}$.

White adipose tissue is considered as an active endocrine organ releasing a variety of biologically active substances termed adipokines, which are known to play key roles in the regulation of glucose / lipid metabolism, insulin sensitivity and inflammation ${ }^{[8]}$. Hence the present study was aimed to investigate the relationship between serum chemerin (as an adipokine), insulin resistance, inflammatory markers and obesity in Egyptian type II diabetics.

\section{Materials and methods \\ Subjects}

This study included 120 Subjects of both sexes classified as 60 healthy and 60 type II diabetic patients. The 60 healthy (not under any medication known to affect glucose metabolism), were subdivided into lean and obese controls (each 30 subjects). Type II diabetic patients enrolled from Ain Shams Hospitals were subdivided into lean and obese diabetics (each 30 patients). All patients had been diagnosed for around one year with T2DM, with controlled blood sugar treated with oral hypoglycemic drugs (sulfonylurease or biguanides) and had normal blood pressure. Patients with any history of smoking, alchol habits, respiratory disorder, thyroid dysfunction and clinically significance infectious disease were excluded from the study. The purpose and the nature of the study were explained to all subjects and written voluntary consents were obtained before their participation. Approval was taken from the research committee of General Organization of Teaching Hospitals and Instituations. The mean ages of lean controls, obese controls, lean diabetics and obese diabetics were 31.2, 47.7, 38.6 and 49.0 respectively. Demographic and clinical data of the controls and type II diabetic patients were listed in (Table 1).

\section{Biochemical parameters}

Five milliliters of venous blood were collected after overnight fasting, serum separated and divided into 3 aliquots as follows: The first part was collected in a tube containing sodium fluoride, centrifuged and plasma separated for determination of fasting plasma glucose. The second part was allowed to clot in plain test tubes, centrifuged (at $3000 \mathrm{rpm}$ for $10 \mathrm{~min}$.). The separated serum was divided into 3 aliquots, were stored at $-20^{\circ} \mathrm{C}$ for subsequent assay of both insulin, and lipids profile, the other 2 aliquots for ELISA assay of chemerin,TNF- $\alpha$ and IL-6.The third part was collected in a tube containing traces EDTA liquid for the measurement of glycated hemoglobin (HbA1c). Hemolysed samples were discarded and repeated freezing and thawing were avoided.

Body mass index (BMI) was calculated as $\mathrm{BMI}=$ Body weight $\mathrm{Kg} /$ height $\mathrm{m}^{2}{ }^{[9]}, \mathrm{BMI}<30$ is lean and $\mathrm{BMI} \geq 30$ is obese. Plasma glucose was determined enzymatically according to the method of Trinder ${ }^{[10]}$ using Stanbio Laboratory, North Main, Boerne, Texas. HbA1c was determined according to the method described by
Trivelli, et. al., ${ }^{[11]}$ using a commercial kit purchased from Stanbio Laboratory, North Main, Boerne, Texas. Serum insulin was determined by ELISA technique using commercial kit, which purchased from (BioSource International, Inc. Europe S.A). Homeostasis model assessment for insulin resistance (HOMA-IR) was calculated using the following equation described by Mathew et al., ${ }^{[12]}$, HOMA-IR= FPG $(\mathrm{mmol} / \mathrm{l}) \mathrm{X}$ fasting serum insulin $(\mu \mathrm{IU} / \mathrm{ml}) / 22.5$. The cutoff point to define insulin resistance corresponds to HOMA-IR $\geq 3.8^{[13]}$. Homeostasis model assessment for $\beta$-cells function (HOMA- $\beta$ ) was calculated using the following equation described by Kanauchi et al., ${ }^{[14]}$, HOMA- $\beta=20 \mathrm{X}$ fasting serum insulin $(\mathrm{mU} / \mathrm{L}) /$ [fasting plasma glucose (mmol/l)-3.5]. Total cholesterol (TC), triacylglycerols (TAGs) and high density lipoprotein-cholesterol (HDLC) were measured colorimetrically as described by Allain et al., ${ }^{[15]}$, Wahlefeld, ${ }^{[16]}$ and Finley et al., [17], respectively. Reagents were obtained from Stanbio Laboratry, North Main, Boerne, Texas, while low density lipoprotein-cholesterol (LDL-C) was calculated by Friedwald's formula ${ }^{[18]}$, LDL-C $=$ total cholesterol(triacylglycerols/5+ HDL-C). Chemerin was determined by ELISA technique using commercial kit which purchased from (Quantikine human chemerin ELISA kit, $\mathrm{R}$ and D Systems, Minneapolis, MN, USA) ${ }^{[19]}$. TNF- $\alpha$ and IL- 6 were determined by ELISA technique using a commercial kit (AviBion, Vantaa, Finland) ${ }^{[20}{ }^{\text {. }}$.

\section{Statistical analysis}

Data are presented as mean \pm SD. The differences between the groups were assessed by one-way ANOVA, followed by Post Hoc test. Associations between the circulating chemerin levels and various parameters were determined using the spearman's rank correlation. Partial correlation analysis was used to control for covariates such as age and BMI. The associations were considered significant at $\mathrm{p}<0.05$. Statistical analysis was performed using IBM, SPSS version 20.0 Inc. Chicago, USA.

\section{Results}

Results presented in (Table 2) show that fasting and postprandial plasma glucose (FPG\&PPPG), HbA1c and HOMA-IR were highly significant increased $(\mathrm{p}<0.001)$ in diabetic patients compared to control subjects. Insulin showed a highly significant decrease $(\mathrm{p}<0.01)$ in lean diabetics, while there was a highly significant increase $(\mathrm{p}<0.001)$ in obese patients and obese controls compared to control subjects. HOMA- $\beta$ showed a highly significant decrease $(p<0.001)$ in diabetic patients, while a highly significant increase $(\mathrm{p}<0.001)$ was recorded between obese and lean subjects.

Lipids profile results in (Table 3) demonstrate that TC, TAGs, LDL-C were highly significant increased $(\mathrm{p}<0.001)$, while HDL-C showed a highly significant decrease $(p<0.001)$ in type two diabetic patients compared to lean controls. In addition, total cholesterol showed a highly significant increase $(\mathrm{p}<0.01)$, while HDL-C showed a highly significant decrease $(\mathrm{p}<0.01)$ in obese subjects compared to lean controls. 
Table 1: Demographic and Clinical data of the controls and type II diabetic patients.

\begin{tabular}{|c|c|c|c|c|c|}
\hline Feature & Group & $\begin{array}{l}\text { I: Lean } \\
\text { normal } \\
\text { controls }\end{array}$ & $\begin{array}{l}\text { II: Lean } \\
\text { diabetics }\end{array}$ & $\begin{array}{c}\text { III: Obese } \\
\text { normal } \\
\text { controls }\end{array}$ & $\begin{array}{l}\text { IV: obese } \\
\text { diabetics }\end{array}$ \\
\hline \multicolumn{2}{|c|}{ Gender (Male / Female) } & $18 / 12$ & $18 / 12$ & $14 / 16$ & $14 / 16$ \\
\hline \multicolumn{2}{|c|}{ Duration of disease (month) } & - & $1-8$ & - & $1-10$ \\
\hline \multirow{2}{*}{ Age (year) } & Range & $30-40$ & $30-60$ & $30-49$ & $40-60$ \\
\hline & M \pm S.D & $(31.2 \pm 3)$ & $(47.7 \pm 7)$ & $(38.6 \pm 7)$ & $(49 \pm 5.5)$ \\
\hline \multirow{2}{*}{ BMI $\left(\mathrm{kg} / \mathrm{m}^{2}\right)$} & Range & $21-29$ & $22-29$ & $30-46$ & $31-50$ \\
\hline & $\mathbf{M} \pm \mathbf{S . D}$ & $(24.7 \pm 2.7)$ & $(24.1 \pm 1.6)$ & $(36.2 \pm 4.7)$ & $(37.5 \pm 5.1)$ \\
\hline
\end{tabular}

BMI=Body mass index

Table 2: FPG, PPPG, HbA1c, insulin, HOMA-IR and HOMA- $\beta$ in lean controls, lean diabetics, obese controls and obese diabetics.

\begin{tabular}{|c|c|c|c|c|c|c|}
\hline & FPG (mg\%) & PPPG (mg\%) & HbA1c (\%) & Insulin $(\boldsymbol{\mu I U} / \mathbf{m l})$ & HOMA-IR & HOMА- $\beta$ \\
\hline \multicolumn{7}{|c|}{ GI: Lean normal controls $(n=30)$} \\
\hline Range & $90-107$ & $125-140$ & $5-6$ & $9-14$ & $2-3$ & $90-147$ \\
\hline M \pm S.D & $(97.8 \pm 4.6)$ & $(131.8 \pm 4.9)$ & $(5.2 \pm 0.4)$ & $(11.4 \pm 1.6)$ & $(2.7 \pm 0.4)$ & $(119.5 \pm 18.4)$ \\
\hline \multicolumn{7}{|c|}{ GII: Lean diabetics $(n=30)$} \\
\hline Range & $260-308$ & $330-380$ & $8-11$ & $6-13$ & $4-9$ & $6-21$ \\
\hline M \pm S.D & $(279 \pm 14)$ & $(349 \pm 12)$ & $(9.4 \pm 1)$ & $(8 \pm 2)$ & $(5.5 \pm 1.5)$ & $(13.3 \pm 4)$ \\
\hline \%change & 185.3 & 164.8 & 80.7 & -29.8 & 103.7 & -88.8 \\
\hline $\mathbf{P}<$ & 0.001 & 0.001 & 0.001 & 0.01 & 0.001 & 0.001 \\
\hline \multicolumn{7}{|c|}{ GIII: Obese normal controls $(\mathrm{n}=\mathbf{3 0}$ ) } \\
\hline Range & 93-111 & $125-140$ & $5-6$ & $12-23$ & $3-6$ & $90-192$ \\
\hline M \pm S.D & $(103.2 \pm 6.8)$ & $(130.5 \pm 5)$ & $(5.2 \pm 0.4)$ & $(16 \pm 3.2)$ & $(3.9 \pm 0.8)$ & $(146.9 \pm 35.7)$ \\
\hline \%change & 5.5 & 0 & 0 & 40.3 & 44.4 & 23 \\
\hline $\mathbf{P}<$ & NS & NS & NS & 0.001 & NS & 0.001 \\
\hline \multicolumn{7}{|c|}{ GIV: Obese diabetics $(n=30)$} \\
\hline Range & $260-310$ & $252-360$ & $8-13$ & $13-23$ & $10-16$ & $20-37$ \\
\hline M \pm S.D & $(281.9 \pm 15.3)$ & $(348.7 \pm 20.4)$ & $(9.5 \pm 1.2)$ & $(17.9 \pm 2.8)$ & $(14.69 \pm 3.57)$ & $(29.7 \pm 5.5)$ \\
\hline \%change & 188.2 & 164.5 & 82.7 & 57 & 363 & -75 \\
\hline $\mathbf{P}<$ & 0.001 & 0.001 & 0.001 & 0.001 & 0.001 & 0.001 \\
\hline
\end{tabular}

Note be: \%Change and $\mathrm{P}$-values were calculated with respect to lean controls, $\mathrm{P}<0.0$ 5: Significant, $\mathrm{P}<0.01$ and $\mathrm{P}<0.001$ : Highly significant and NS: Non significant. FPG: fasting plasma glucose, PPPG: post prandial plasma glucose, HbA1c: glycated hemoglobin, HOMA-IR: homeostasis model assessment for insulin restistance and HOMA- $\beta$ : homeostasis model assessment for $\beta$-cells function. 
Table 3: Serum lipids profile in lean normal controls, lean diabetics, obese normal controls and obese diabetics.

\begin{tabular}{|c|c|c|c|c|}
\hline & $\mathrm{TC}(\mathrm{mg} \%)$ & TAGs (mg\%) & HDL-C (mg\%) & LDL-C (mg\%) \\
\hline \multicolumn{5}{|c|}{ GI: Lean normal controls $(n=30)$} \\
\hline Range & $180-209$ & $90-110$ & $46-56$ & $90-139$ \\
\hline M \pm S.D & $(194.7 \pm 11.6)$ & $(98 \pm 7.2)$ & $(50 \pm 2.6)$ & $(122.2 \pm 15.4)$ \\
\hline \multicolumn{5}{|c|}{ GII: Lean diabetics $(n=30)$} \\
\hline Range & $275-340$ & $158-210$ & $31-45$ & $101-267$ \\
\hline M \pm S.D & $(302 \pm 20.6)$ & $(174 \pm 16.5)$ & $(39.4 \pm 4.2)$ & $(173.7 \pm 51.6)$ \\
\hline \%change & 55 & 77.5 & -21.2 & 42 \\
\hline $\mathbf{P}<$ & 0.001 & 0.001 & 0.001 & 0.001 \\
\hline \multicolumn{5}{|c|}{ GIII: Obese normal controls $(n=30)$} \\
\hline Range & $180-262$ & $98-120$ & $40-52$ & $117-190$ \\
\hline M \pm S.D & $(225.2 \pm 22.6)$ & $(106.4 \pm 6.3)$ & $(45.8 \pm 4.6)$ & $(158 \pm 23.2)$ \\
\hline \%change & 15.6 & 8.6 & -8.4 & 29.3 \\
\hline $\mathbf{P}<$ & 0.01 & NS & 0.01 & NS \\
\hline \multicolumn{5}{|c|}{ GIV: Obese diabetics $(n=30)$} \\
\hline Range & $278-434$ & $165-287$ & $29-40$ & $205-353$ \\
\hline M \pm S.D & $(342.5 \pm 44)$ & $(194.9 \pm 29.7)$ & $(35.4 \pm 3.8)$ & $(268.4 \pm 42)$ \\
\hline \%change & 76 & 98.8 & -29.2 & 119.6 \\
\hline $\mathbf{P}<$ & 0.001 & 0.001 & 0.001 & 0.001 \\
\hline
\end{tabular}

\%Change and P-values were calculated with respect to lean normal controls (GI). P $<0.01 \&$ P $<0.001$ : Highly significant and NS: Non significant. TC: total cholesterol,TAG: triacylglycerols, HDL-C: high density lipoprotein-cholesterol and LDLC: low density lipoprotein-cholesterol

Table 4: Serum chemerin, TNF- $\alpha$ and IL-6 in lean normal controls, lean diabetics, obese normal controls and obese diabetics.

\begin{tabular}{|c|c|c|c|}
\hline & Chemerin $(\mathrm{pg} / \mathrm{ml})$ & TNF- $\alpha(\mathrm{pg} / \mathrm{ml})$ & IL-6 (pg/ml) \\
\hline \multicolumn{4}{|c|}{ GI: Lean normal controls $(\mathbf{n}=30)$} \\
\hline Range & $600-850$ & $6-10$ & $7-12$ \\
\hline M \pm S.D & $(724.6 \pm 86)$ & $(7.7 \pm 1.7)$ & $(9.2 \pm 1.6)$ \\
\hline \multicolumn{4}{|c|}{ GII: Lean diabetics $(n=30)$} \\
\hline Range & $900-1200$ & $8-16$ & $15-21$ \\
\hline M \pm S.D & $(1061 \pm 112)$ & $(12 \pm 2.4)$ & $(18.3 \pm 1.9)$ \\
\hline \%change & 46.4 & 55.8 & 99 \\
\hline $\mathbf{P}<$ & 0.001 & 0.001 & 0.001 \\
\hline \multicolumn{4}{|c|}{ GIII: Obese normal controls $(\mathbf{n}=30)$} \\
\hline Range & $800-1000$ & 8-16 & $10-18$ \\
\hline M \pm S.D & $(900 \pm 75.5)$ & $(10.8 \pm 2.6)$ & $(14 \pm 2.6)$ \\
\hline \%change & 24.2 & 40.2 & 50.5 \\
\hline $\mathbf{P}<$ & 0.01 & 0.05 & 0.01 \\
\hline \multicolumn{4}{|c|}{ GIV: Obese diabetics $(n=30)$} \\
\hline & $1000-1650$ & $14-25$ & $17-30$ \\
\hline \multicolumn{4}{|l|}{ Range } \\
\hline M \pm S.D & $(1311 \pm 212.7)$ & $(17.9 \pm 3.9)$ & $(24 \pm 5.8)$ \\
\hline \%change & 81 & 132.5 & 160.8 \\
\hline $\mathbf{P}<$ & 0.001 & 0.001 & 0.001 \\
\hline
\end{tabular}

\%Change and $\mathrm{P}$ values were calculated with respect to lean normal controls (GI). $\mathrm{P}<0.0$ 5: Significant, $\mathrm{P}<0.01 \& \mathrm{P}<0.001$ : Highly significant. TNF- $\alpha$ : tumor necrosis factor- $\alpha$ and IL-6: interleukin-6. 
Table (4) indicated that chemerin, TNF- $\alpha$ and IL-6 were high significantly increased $(p<0.001)$ in diabetic patients compared to control subjects. Also a highly significant increase $(\mathrm{p}<0.01)$ was recorded about chemerin and IL-6, although TNF- $\alpha$ showed a significant increase $(\mathrm{p}<0.05)$ in obese subjects compared to lean controls.

Table (5) showed the Spearman's rank correlation $\left(r_{s}\right)$ between serum chemerin levels and other studied parameters in diabetic patients, significant positive correlations were found between chemerin and age $\left(r_{\mathrm{s}}=\right.$ $0.647, \quad \mathrm{P}<0.001), \quad$ BMI $\quad\left(\mathrm{r}_{\mathrm{s}}=0.304, \quad \mathrm{P}<0.01\right), \quad$ FPG $\left(r_{s}=0.629, P<0.001\right)$, PPPG $\left(r_{s}=0.641, P<0.001\right)$, HbA1c $\left(r_{s}=0.634, \quad P<0.001\right)$, insulin $\left(r_{s}=0.286, \quad P<0.01\right)$, HOMA-IR $\left(\mathrm{r}_{\mathrm{s}}=0.796, \mathrm{P}<0.001\right), \mathrm{TC}\left(\mathrm{r}_{\mathrm{s}}=0.783, \mathrm{P}<0.001\right)$, TAGs $\left(\mathrm{r}_{\mathrm{s}}=0.774, \mathrm{P}<0.001\right)$, LDL-C $\left(\mathrm{r}_{\mathrm{s}}=0.711, \mathrm{P}<0.001\right)$, TNF- $\alpha \quad\left(r_{s}=0.698, \quad P<0.001\right) \quad$ and $\quad$ IL-6 $\quad\left(r_{s}=0.693\right.$, $\mathrm{P}<0.001$ ). Moreover, a negative correlation was found between chemerin and HOMA- $\beta\left(r_{s}=0.464, \mathrm{P}<0.001\right)$ and HDL-C $\left(r_{s}=0.732, \quad P<0.001\right)$. However, a non significant correlation was recorded between serum chemerin and sex.

Also, table (5) showed that the correlation between the chemerin and other studied parameters remained significant after adjustment for BMI and age in partial correlation analysis (this was done electronically by the SPSS program). A significant positive correlation was recorded between chemerin and FPG $\left(\mathrm{r}^{\mathrm{b}}=0.496\right.$, $\mathrm{p}<0.001)$, PPPG $\left(\mathrm{r}^{\mathrm{b}}=0.501, \mathrm{p}<0.001\right), \mathrm{HbA1}\left(\mathrm{r}^{\mathrm{b}}=0.362\right.$, $\mathrm{p}<0.01)$, insulin $\left(\mathrm{r}^{\mathrm{b}}=0.266, \mathrm{p}<0.05\right)$, HOMA-IR $\left(\mathrm{r}^{\mathrm{b}}=\right.$ $0.600, \mathrm{p}<0.001)$, total cholesterol $\left(\mathrm{r}^{\mathrm{b}}=0.489, \mathrm{p}<0.001\right)$, TAGs $\left(\mathrm{r}^{\mathrm{b}}=0.511, \mathrm{p}<0.001\right)$, LDL-C $\left(\mathrm{r}^{\mathrm{b}}=0.491\right.$, $\mathrm{p}<0.001)$, TNF- $\alpha\left(\mathrm{r}^{\mathrm{b}}=0.443, \mathrm{p}<0.001\right), \mathrm{IL}-6\left(\mathrm{r}^{\mathrm{b}}=0.357\right.$, $\mathrm{p}<0.01)$. Moreover, a negative correlation was found between chemerin and HOMA- $\beta\left(\mathrm{r}^{\mathrm{b}}=0.428, \mathrm{p}<0.001\right)$ and HDL-C $\left(\mathrm{r}^{\mathrm{b}}=0.395, \mathrm{p}<0.001\right)$.

Note that: this correlation is done in diabetic patients to show the association between chemerin and other studied parameters (the aim of the study) and the difference between serum chemerin levels in different groups is shown in table (4).

Table 5: Correlation between serum chemerin levels and other studied parameters in diabetic patients $(n=60)$.

\begin{tabular}{|c|c|c|c|c|}
\hline \multirow{2}{*}{ Parameter } & \multicolumn{4}{|c|}{ Chemerin pg/ml } \\
\hline & $\mathbf{r}_{\mathrm{s}}$ & $\mathbf{P}$ & $\mathbf{r}^{\mathbf{b}}$ & $\mathbf{P}^{\mathbf{b}}$ \\
\hline Sex (male /female) & 0.04 & $>0.05$ & -0.113 & $>0.05$ \\
\hline Age (year) & 0.647 & $<0.001$ & - & - \\
\hline BMI $\left(\mathrm{kg} / \mathrm{m}^{2}\right)$ & 0.304 & $<0.01$ & - & - \\
\hline FPG (mg\%) & 0.629 & $<0.001$ & 0.496 & $<0.001$ \\
\hline PPPG (mg\%) & 0.641 & $<0.001$ & 0.501 & $<0.001$ \\
\hline HbA1c (\%) & 0.634 & $<0.001$ & 0.362 & $<0.01$ \\
\hline Insulin ( $\boldsymbol{\mu I U} / \mathbf{m l})$ & 0.286 & $<0.01$ & 0.266 & $<0.05$ \\
\hline HOMA-IR & 0.796 & $<0.001$ & 0.600 & $<0.001$ \\
\hline НОМА- $\beta$ & -0.464 & $<0.001$ & -0.428 & $<0.001$ \\
\hline T. cholesterol (mg\%) & 0.783 & $<0.001$ & 0.489 & $<0.001$ \\
\hline TAGs (mg\%) & 0.774 & $<0.001$ & 0.511 & $<0.001$ \\
\hline HDL-C (mg\%) & -0.732 & $<0.001$ & -0.395 & $<0.001$ \\
\hline LDL-C (mg\%) & 0.711 & $<0.001$ & 0.491 & $<0.001$ \\
\hline TNF- $\alpha(\mathrm{pg} / \mathrm{ml})$ & 0.698 & $<0.001$ & 0.443 & $<0.001$ \\
\hline IL-6 (pg/ml) & 0.693 & $<0.001$ & 0.357 & $<0.01$ \\
\hline
\end{tabular}

Spearman's rank correlation (rs) was performed for serum chemerin levels and the indicated parameter. Partial correlation analysis (rb) was performed for serum chemerin levels after adjustment for BMI and age. $\mathrm{P}<0.05$ : significant, $\mathrm{P}<0.01 \& \mathrm{P}<0.001$ : Highly significant and P > 0.05: Non significant.BMI: body mass index, FPG: fasting plasma glucose, PPPG: post prandial plasma glucose, HbA1c: glycated hemoglobin, HOMA-IR:homeostasis model assessment for insulin restistance, HOMA- $\beta$ : homeostasis model assessment for $\beta$-cells function,TC: total cholesterol, TAG: triacylglycerols, HDL-C: high density lipoprotein-cholesterol, LDL-C: low density lipoprotein-cholesterol, TNF- $\alpha$ : tumor necrosis factor- $\alpha$ and IL-6: interleukin-6. 


\section{Discussion}

Chemerin is an adipocyte secreted protein with autocrine and paracrine roles on adipose tissue development and function as well as endocrine roles in metabolism and immunity. The dual role of chemerin in inflammation and metabolism might provide a link between chronic inflammation and obesity, as well as obesity-related disorders such as type 2 diabetes and cardiovascular disease ${ }^{[21]}$.The present study was undertaken to investigate the relationship between serum chemerin, insulin resistance, inflammatory markers and obesity in Egyptian type II diabetics.

In obesity, adipose tissue expansion involves a number of remodelling processes that include the enlargement of existing adipocytes (hypertrophy) and an increase in adipocyte number (hyperplasia). One mechanism that contributes to adipocyte hyperplasia is the increased proliferation and differentiation of preadipocytes into adipocytes ${ }^{[8]}$. In this study, chemerin was positively correlated with BMI, this could be explained by the fact that chemerin signaling is essential during the early clonal expansion phase of adipocyte differentiation. Also it supports adipose tissue expansion by inducing angiogenesis and promoting vascularization ${ }^{[8]}$.

In the present study, it was revealed that serum chemerin levels were significantly increased in obese individuals compared with lean controls and were positively correlated with adiposity measures (BMI).These results are in agreement with Coimbra et al., ${ }^{[22]}$ and Herova et al., ${ }^{[23]}$ who reported that serum chemerin levels were significantly increased in obese individuals and positively correlated with the body mass index, waist circumference, abdominal visceral fat area Furthermore, obese patients who underwent weight loss through either bariatric surgery or exercise-nutrition-based methods exhibited a significant decline of circulating serum chemerin. This supports that the obesity-associated increase in chemerin levels appears to be primarily adipose tissue derived ${ }^{[22,23]}$.

The glycaemic threshold for diagnosis is settled according to the American Diabetes Association guidelines for diagnosis of diabetes mellitus ${ }^{[24]}$. Results of the present study revealed that FPG, PPPG and $\mathrm{HbAlc}$ were elevated in all diabetic patients, while serum insulin was elevated in obese controls and diabetics compared to both lean controls and lean diabetics patients. On the other hand it was decreased in lean diabetics compared to lean controls, as diabetic patients with abdominal obesity display peripheral insulin resistance in combination with defective insulin secretion, where as non- obese diabetic patients show only a secretory defect. Thus, type 2 diabetes in obese and non-obese may take two forms where the cause of hyperglycaemia differs ${ }^{[25]}$. These results are in concordant with Destefano et al., ${ }^{[26]}$ and Pories et al., ${ }^{[27]}$ who documented that fasting insulin levels increase as subjects progress from obesity to impaired glucose tolerance and severe diabetes compared with lean control subjects. Parallel results were also reported by
Arner et al., ${ }^{[25]}$ who demonstrated that obese diabetic patients have reduction in insulin sensitivity and a preserved insulin release, while non-obese patients have a reduction in insulin release and normal insulin sensitivity.

Insulin resistance is a condition in which a higher than normal insulin concentration is needed to achieve normal metabolic responses. It may be either peripheral (which refers to diminished insulin-mediated uptake of glucose by skeletal muscle and depends primarily on the failure of glucose transporter type 4 expression and translocation to the plasma membrane) or hepatic insulin resistance (which describes impaired suppression of hepatic glucose production and largely accounts for hyperglycemia and glucose intolerance) ${ }^{[28]}$.

The HOMA-IR has proved to be a robust tool for the surrogate assessment of insulin resistance and the cutoff point to define insulin resistance corresponds to HOMAIR $\geq 3.8^{[13]}$. HOMA-IR levels showed a highly significant elevation in obese than lean type II diabetic patients, while non significant results were recorded in obese compared to lean controls, this could be due to excessive lipolysis and release of free fatty acids from enlarged adipose tissue and secretion of inflammatory factors and specific adipocytokines ${ }^{[29]}$. Increasing circulating free fatty acids metabolites such as diacylglycerol, fatty acyl CoA's, or ceramides activates serine/threonine kinase protein kinase $\mathrm{C}-\mathrm{h}$, leading to the phosphorylation of serine/threonine sites on insulin receptor substrates (IRS1 and IRS-2), which then inhibits the insulin signaling cascade ${ }^{[30]}$. This result goes hand in hand with Lebovitz and Banerji, ${ }^{[31]}$ who stated that hyperinsulinemia, is the normal compensatory response to insulin resistance. If the hyperinsulinemia is sufftcient to overcome the insulin resistance, glucose regulation remains normal, if not type 2 diabetes develop ${ }^{[31]}$.

HOMA- $\beta$, is a surrogate estimate of pancreatic beta-cell function and based on measurements of fasting plasma glucose and insulin concentrations. In non-diabetic subjects, increased insulin resistance increases insulin secretion to maintain plasma glucose level within the normal range. HOMA- $\beta$ level showed a significant decrease in all type II diabetic patients, while it recorded a highly significant increase in obese compared to nonobese controls, this is due to the fact that insulin secretion is correlated with insulin sensitivity in non diabetic subjects ${ }^{[32]}$. This is in accordance with De Fronzo et al., ${ }^{[33]}$ who reported that when $\beta$ cell fails to maintain insulin secretion against insulin resistance, relative insulin deficiency leads to impaired glucose tolerance or diabetes.

The highly significant positive correlations between serum chemerin, FPG, PPPG, insulin, HOMA-IR and a significant negative correlation with HOMA- $\beta$ in the present study could be explained in term of: Firstly, higher chemerin release is associated with insulin resistance by decreasing the rate of auto-phosphorylation and subsequent downstream intracellular signaling cascades of insulin receptor-tyrosine kinase in peripheral 
tissues and increasing the basal serine phosphorylation of IRS-1. This IRS-1 serine site is known to negatively modulate insulin action. Secondly, chemerin inhibits glycogen synthase kinase 3 phosphorylation (an enzyme necessary for glycogen synthesis and storage) and thus inhibits glucose uptake. Thirdly, chemerin activates extracellular signal-regulated kinase (ERK), activation of ERK activates chemerin-induced insulin resistance [34]

Chemerin regulates adipocyte differentiation and modulates a dipocytes expression of several pivotal genes involved in lipid homoeostasis such as; glucose transporter-4, diacylglycerol O-acyltransferase-2, fatty acid synthase, adiponectin and leptin These observations suggest that chemerin may be a regulator of lipid metabolism ${ }^{[35]}$. This was proved in this study by the positive correlations of chemerin with TC, TAGs, LDL$\mathrm{C}$ and the negative correlation with HDL-C. These results go hand in hand with previous studies who reported significant positive correlations between chemerin and total cholesterol, triglycerides, LDL-C and a negative correlation between chemerin and HDL-C c $[2,23 \& 36]$

Increased adiposity induces chronic low-grade inflammation in adipose tissue, which is causally linked to obesity itself, as well as many obesity-associated comorbidities. Results of the present study revealed that IL-6 and TNF- $\alpha$ levels showed a highly significant elevation in obese than lean type II diabetic patients and in obese controls compared to lean controls, this could be explained by the fact that adipose tissue is composed of adipocytes, preadipocytes (which are immature adipocytes that have not yet loaded any lipids), endothelial cells, leukocytes, fibroblasts, and macrophages. During obesity, lipid accumulation causes a high degree of stress on adipocytes, activating them, promoting the production and subsequent release of free fatty acids, proinflammatory adipocytokines (such as leptin and resistin), cytokines, such as IL-1 $\beta$, IL-6, TNF$\alpha$, as well as reactive oxygen species, ensuring that in addition to its well-known capacity to store energy, adipose tissue has the capability to function as an endocrine organ. In fact, this endocrine ability of adipose tissue triggers inflammation, leading to insulin resistance and the development of T2DM ${ }^{[37]}$.

These results are in accordance with Rajarajeswari et al., ${ }^{[38]}$ who reported that TNF- $\alpha$ was significantly high in obese T2DM than in non obese subjects and increased levels of TNF- $\alpha$ were associated with increased levels of glucose in T2DM and was related to the degree of obesity. In addition, Kern et al., ${ }^{[39]}$ showed that plasma levels of IL-6 are2-3 folds higher in obese type 2 diabetes than in lean control subjects. Moreover, Kern et al., ${ }^{[39]}$ stated that this elevation is highly related to increased blood glucose, decreased glucose tolerance and decreased insulin sensitivity.

Results of the present study revealed that serum chemerin levels were positively correlated with serum levels of pro-inflammatory cytokines including IL-6 and
TNF- $\alpha$, this may rise as a consequence of increased expression of these pro-inflammatory cytokines which have an established role in up-regulating chemerin expression and bioactivation in adipocytes ${ }^{[8]}$. Our results are in accordance with Herova et al., ${ }^{[23]}$ who stated that serum chemerin levels are positively correlated with serum levels of a number of pro-inflammatory cytokines (IL-6 and TNF- $\alpha$. and leptin).

The significant positive correlation that was found between chemerin and age is due to adipose tissue dysfunction that occurred and enhanced with age. The age is also associated with increasing insulin resistance, weight and adiposity gain ${ }^{[22]}$. The significant positive correlation between chemerin and age is agreement with Coimbra et al., ${ }^{[22]}$ and Aronis et al., ${ }^{[40]}$, who demonstrated that aging is associated with increasing insulin resistance, weight, and adiposity gain. They also found that aging in T2DM patients is associated with an altered adipokine secretion, as shown by the significant and positive correlations with leptin, chemerin and the inverse correlation with adiponectin. Thus in T2DM, independently of BMI, a dysfunction in adipose tissue occurs and is enhanced with age. They also showed that older T2DM patients (65-85 years) have higher chemerin levels compared to middle-aged T2DM group (38-64 years) and to controls (matched for age with the middleaged T2DM group), these results strengthen the proposal that chemerin increases insulin resistance, which increases with age. After statistical adjustment for length of disease, the significant increase of chemerin levels in the oldest T2DM group remained significant, suggesting that chemerin levels are dependent on age ${ }^{[22,40]}$.

\section{Conclusion}

In conclusion, results of the present study revealed that type 2 diabetic patients and obese subjects exhibited a highly significant increase in serum chemerin. In addition, serum chemerin was positively correlated with age, BMI, FPG, PPPG, HbA1c, insulin, HOMA-IR, TC, TAGs, LDL-C,TNF- $\alpha$ and IL-6. Moreover, a negative correlation was found between serum chemerin, HOMA$\beta$ and HDL-C. These results provide an evidence for association of serum chemerin with insulin resistance, inflammation and obesity in Egyptian type II diabetic patients.

\section{References}

1) International Diabetes Fedration (2014). IDF diabetes atals, sixth edition. Website: http://www.idf.org/ diabetesatals/update/2014.

2) Yan, Q., Zhang, Y., Hong, J., Gu W., Dai, M., Shi, J., Zhai,Y., Wang, W., Li, X. and Ning, G. (2012). The association of serum chemerin level with risk of coronary artery disease in Chinese adults. End., 41(2): 281-288.

3) Conde, J., Scotece, M., Gomez, R., Lopez, V., Gomez, R. J., Lago, F. and Gualillo O. (2011). Adipokines: biofactors from white adipose tissue. A complex hub among inflammation, metabolism and immunity. Biofact., 37(6): 413-420. 
4) Qatanani, M. and Lazar M. A. (2007). Mechanisms of obesity-associated insulin resistance: many choices on the menu. Genes Dev., 21(12): 1443-1455.

5) Roh, S., Song, S. H., Choi, K. C., Katoh, K., Wittamer, V. and Parmentier, M. (2007). Chemerin a new adipokine that modulates adipogenesis via its own receptor. Biochem. Biophys. Res. Commun., 362(4): 1013-1018.

6) Goralski, K. B., McCarthy, T. C., Hanniman, E. A., Zabel, B. A., Butcher, E. C., Parlee, S. D., Muruganandan, S. and Sinal, C. J. (2007). Chemerin, a novel adipokine that regulates adipogenesis and adipocyte metabolism. J. Biol. Chem., 282(38): 28175-28188.

7) Chakaroun, R., Raschpichler, M., Klöting, N., Oberbach, A., Flehmig, G., Kern, M., Schön, M. R., Shang, E., Lohmann, T., Drebler, M. and Fasshauer, M. (2012). Effects of weight loss and exercise on chemerin serum concentrations and adipose tissue expression in human obesity. Metab., 61(5): 706-714.

8) Rourke, J. L., Dranse, H. and Sinal, C. J. (2013). Towards an integrative approach to understanding the role of chemerin in human health and disease. Obesity Reviews, 14: 245-262.

9) Eknoyan, G. (2008). Adolphe Quetelet (17961874) the average man and indices of obesity. Nephrol. Dial. Transplant. 23(1): 47-51.

10) Trinder, P. (1969). Determination of blood glucose using 4-minophenazone. J. Clin. Pathol., 22(2): 246.

11) Trivelli, L. A., Ranney, H. M. and Lai, H. T. (1971). Hemoglobin components in patients with diabetes mellitus. N. Eng. J. Med., 284: 353-357.

12) Matthews, D. R., Hosker, J. P, Rudenski, A. S., Naylor, B. A, Treacher, D. F. and Turner, R. C. (1985). Homeostasis model assessment: insulin resistance and B-cell function from plasma glucose and insulin concentrations in man. Diabetol., 28: 412-419.

13) Qu, H. Q., Quan, L., Anne, R., Susan, P., McCormick, F. H. and Joseph, B. (2011). The definition of insulin resistance using HOMA-IR for Americans of Mexican descent using machine learning. Plos One, 6(6): e21041.

14) Kanauch, M., Yamano, S., Kanauchi, K. and Saito, Y. (2003). Homeostasis model assessment of insulin resistance, quantitative insulin sensitivity check index and oral insulin sensitivity index in non-obese, non-diabetic subjects with high-normal blood pressure. J. Clin. Endocrinol. Metab. 88(7): 3444-3446.

15) Allain, C. C., Poon, L. S., Chan, C. S., Richmond, R. and Fu, P. C. (1974). Enzymatic determination of total serum cholesterol. Clin. Chem., 20: 470475.

16) Wahlefeld, A. W. (1974). Triglycerides determination after enzymatic hydrolysis.
Bergmeyer H.U., editor: Methods of enzymatic analysis. NY. Academic Press, 4: 1831-1835.

17) Finley, P. R., Schifman, R. B., Williams, R. J. and Lichti, D. A. (1978). Cholesterol in high-density lipoprotein: Use of $\mathrm{Mg}_{2} /$ dextran sulfate in its enzymic measurement. Clin. Chem., 24: 931-933.

18) Friedwald, W. T., Levy, R. I. and Fridrickson, D. S. (1972). Estimation of the concentration of lowdenisty lipoprotein cholesterol in plasma without use of the preparative ultracentrifugation. Clin. Chem., 18: 449-501.

19) Albanesi, C., Scarponi, C., Pallotta, S., Daniele, R., Bosisio, D., Madonna, S., Fortugno, P., Feo, S. G., Franssen, J. D., Parmentier, M., Pità, O. D., Girolomoni, G. and Sozzani, S. (2009). Chemerin expression marks early psoriatic skin lesions and correlates with plasmacytoid dendritic cell recruitment. J. Exp. Med., 206 (1): 249-258.

20) Pinto, A., Tuttolomondo, A., Casuccio, A., Raimondo, D. I., Sciacca, D. I., Valentina, A. and Giuseppe, L. (2009). Immuno-inflammatory predictors of stroke at follow-up in patients with chronic non-valvular atrial fibrillation. Clin. Sci., 116: 781-789.

21) Ernst, M. C. and Sinal, C. J. (2010). Chemerin: at the crossroads of inflammation and obesity. Trends Endocrinol. Metab., 21(11): 660-667.

22) Coimbra, S., Proença, J. B., Silva, A. S. and Neuparth, M. J. (2014). Adiponectin, Leptin, and Chemerin in elderly patients with type 2 diabetes mellitus:A close linkage with obesity and length of the disease. Bio. Med. Res. Int., 2014: 1-8.

23) Herova, M., Schmid, M., Gemperle, C., Loretz, C. and Hersberger, M. (2014). Low dose aspirin is associated with plasma chemerin levels and may reduce adipose tissue inflammation. Atheroscl., 235(2): 256-262.

24) American Diabetes Association, (2014). Standards of medical care in diabetes. Diabet. Care., 37(suppl. 1): s14 - s80.

25) Arner, P., Pollare, T. and Lithell, H. (1991). Different aetiologies of type 2 (non-insulindependent) diabetes mellitus in obese and non-obese subjects. Diabetol., 34: 483-487.

26) Destefano, M. B., Stern, J. S. and Castonguay, T. W. (1991). Effect of chronic insulin administration on food intake and body weight in rats. Physiol. Behav., 50: 801-806.

27) Pories, W. J., MacDonald, K. G., Morgan, E. J., Sinha, M. K., Dohm, G. L., Swanson, M. S., Barakat, H. A., Khazanie, P. G., Frazier, N. L., Long, S. D., Brien, K. F. and Caro, J. F. (1992). Surgical treatment of obesity and its effect on diabetes: 10 year follow-up. Am. J. Clin. Nutr. 55(Suppl. 2): s582 - s585.

28) Abdel-Rahman, E. (2010). Insulin resistance. Arab Journal of Gastroenterology, 11: 66-69. 
29) Bergmann, K. and Sypniewska, G. (2013). Diabetes as a complication of adipose tissue dysfunction. Is there a role for potential new biomarkers? Clin. Chem. Lab. Med., 51(1): 177185.

30) Zeyda, M. and Stulnig, T. M. (2009). Obesity, inflammation and insulin resistance, a mini review. Gerontol., 55: 379-386.

31) Lebovitz, H. E. and Banerji, M. A. (2001). Insulin resistance and its treatment by thiazolidinediones. Endo. Soci., : 265-294.

32) Mari, A., Ahrén, B. and Pacini, G. (2005). Assessment of insulin secretion in relation to insulin resistance. Curr. Opin. Clin. Nutr. Metab. Care; 8: 529-533.

33) Defronzo, R. A., Bonadonna, R. C. and Ferrannini, E. (1992). Pathogenesis of NIDDM. A balanced overview. Diabet. Care; 15: 318-368.

34) Sell, H., Laurencikiene, J., Taube, A., Eckardt, K., Cramer, A., Horrighs, A., Arner, P. and Eckel, J., (2009). Chemerin is a novel adipocytederived factor inducing insulin resistance in primary human skeletal muscle cells. Diabet., 58: 27312740.

35) Shin, H. Y., Lee, D. C., Chu, S. H., Jeon, J. Y., Lee, M. K., Im, J. A. and Lee, J. W. (2012).
Chemerin levels are positively correlated with abdominal visceral fat accumulation. Clin. Endocrinol., 77: 47-50.

36) Ali, T M. and Al Hadidi, K. (2013). Chemerin is associated with markers of inflammation and predictors of atherosclerosis in Saudi subjects with metabolic syndrome and type 2 diabetes mellitus. B. J. B. A. S., 2(2): 86-95.

37) Jiménez, A. E., Peón, A. N. and Terrazas, L. I. (2012). Alternatively activated macrophages in types 1 and 2 diabetes. Mediat. Inflamm., 2012: 1-10.

38) Rajarajeswari, D., Ramalingam, K., Krishnamma, M. and Krishna, T. S. (2011). Association of TNF- $\alpha$ with obesity in T2D. Int. J. Pharma. Bio. Sci., 2(2): b352 - b357.

39) Kern, P.A., Ranganathan, S., Li, C., Wood, L. and Ranganathan, G. (2001). Adipose tissue tumor necrosis factor alpha and interleukin-6 expression in human obesity and insulin resistance. Am. J. Physiol. Endocrinol. Metab., 280: e745-e751.

40) Aronis, K. N., Efe, A. S., Chamberland, J. P., Spiro, A., Vokonas, P. and Mantzoros, C. S. (2014). Chemerin levels as predictor of acute coronary events: a case-control study nested within the veterans' affairs normative aging study. Metab., 63(6): 760-766. 